\title{
Do Danish Maritime Doctors Value Continuous Education Initiatives?
}

\section{Despena Andrioti ${ }^{1}$, Mads D Faurby ${ }^{1}$, Jette Videbæk Le ${ }^{2}$ and Olaf C Jensen ${ }^{1}$}

${ }^{1}$ Centre of Maritime Health and Society, Institute of Public Health, School of Health Sciences, University of Southern Denmark, Esbjerg, Denmark ${ }^{2}$ Research Unit of General Practice, Institute of Public Health, School of Health Sciences, University of Southern Denmark, Denmark

\begin{abstract}
Aims and objectives: Seagoing employees must undergo medical examinations every second year. Even though International Organisations issued guidelines for these pre-employment medical examinations there is a lack of an internationally accepted continuous training programme for the maritime doctors who perform these examinations. The aim of this survey was to examine the Danish maritime doctors perceived training needs as part of a planned comprehensive maritime occupational health prevention programme.
\end{abstract}

Methods: A questionnaire based on international standards was distributed to all the maritime doctors (110) electronically in May 2017. The completed questionnaires were $46.4 \%$. STATA was used for the statistical analysis of the data and correlations among the self-rated needs as dependent variables and the doctors characteristics were performed with Fisher exact test, with significance level at $\alpha=0.05 \%$.

Results: The maritime doctors considered very important to receive training in "Fitness evaluation and medical examinations guidelines" (76.47\%) followed by "Rules and regulations within maritime medicine" (68.63\%) and "Working conditions and health risks on board" $(62.75 \%)$. The number of examinations influenced their preference with those with more than 20 patients to express a more pressing need for training. Age, gender and years of practice did not have any influence in their self-rated needs. Furthermore, they pointed out flexible ways of training including distance learning and the establishment of a webpage by the respective Authorities as one stop-shop.

Conclusion: Maritime doctors are in favour of continuous education and training. The survey may help the respective Authorities to organise such short courses on targeted topics in the country.

Keywords: Seafarers; Fishermen; Off-shore; Seagoing

\section{Introduction}

There are about 1.5 million seafarers who sail around the globe, for long periods of time, transporting more than 90 per cent of goods $[1,2]$. The maritime employees are a hard to reach population group since their work imposes difficulties to seek timely health services $[3,4]$. Seafarers, fishermen and off-shore workers are prone to mandatory health examinations every second year in order to reduce risks to other crew members and for the safe operation of the ship as well as to protect their personal health and safety. The aim of regular health examinations are to decide if the seafarer is medically fit to perform his or her routine and emergency duties at sea and is not suffering from a medical condition likely to deteriorate at sea [5]. The fitness for work examinations must be conducted by a maritime doctor, who should be familiar with the health risks of seafarers and working environment on board merchant vessels [5,6]. In addition to the maritime doctor seagoing employees may consult their regular General Practitioner (GP) with regards to health concerns.

The International LabourOrganisation(ILO) in the MaritimeLabour Convention (MLC) 2006, which entered into force internationally and in Denmark 20 August 2013, stated that countries should have specific guidelines on the medical examination of seafarers and fishermen [6]. ILO has issued guidelines on the medical examination of seafarers that all member countries should apply to [5]. The current Danish executive order on the medical examination of seafarers and fishermen no. 999 enters into force in 2016 [7]. The executive order takes into account the guidelines issued by ILO and MLC 2006, the amendments, as well as the requirements of the Standards of Training Certification and Watch Keeping (STCW) Convention, 1978 [5,6].

In Denmark maritime doctors are GPs, appointed by the Danish Maritime Authority (DMA) to provide pre-employment health examinations to seagoing personnel [8]. Further training in maritime medicine, is not provided in the country. Denmark lacks a specific training programme in maritime medicine for medical doctors.

Maritime doctors who wish to pursue such courses have to travel abroad and more likely to neighbouring countries. It can be argued that regular GPs may need more detailed guidance in dealing with professionals who work at sea and should receive training in maritime medicine, as the seagoing professionals might consult their regular GP with health concerns [5].

Education and training of health professionals is an essential factor in the development of health systems [9]. Education and training contribute to better responsiveness and performance of the health professionals and lead to optimization of the services $[10,11]$. In addition, the doctors strengthen their skills to provide the patients with guidelines for modification of their behavioural choices and the self-management of their illness. This will further strengthen the implementation of integrated care. The National Health System in Denmark will benefit from improving the access to care of hard to reach groups and lower hospitalizations. More specifically maritime doctors, play a fundamental role including the performance of health examinations, communication with authorities and the follow-up practices $[12,13]$.

${ }^{*}$ Corresponding author: Despena Andrioti, Centre of Maritime Health and Society, Institute of Public Health, School of Health Sciences, University of Southern Denmark Niels Bohrs Vej 9, 6700 Esbjerg, Denmark, E-mail: dandrioti@health.sdu.dk

Received August 22, 2017; Accepted August 29, 2017; Published September 08, 2017

Citation: Andrioti D, Faurby MD, Le JV, Jensen OC (2017) Do Danish Maritime Doctors Value Continuous Education Initiatives? Health Econ Outcome Res Open Access 3: 137. doi: 10.4172/2471-268X/1000137

Copyright: $\odot 2017$ Andrioti D, et al. This is an open-access article distributed under the terms of the Creative Commons Attribution License, which permits unrestricted use, distribution, and reproduction in any medium, provided the original author and source are credited. 
However, the guidelines on pre-engagement health examinations did not take into consideration the medical doctor's perspective in terms of training. Due to the global nature of shipping this training should be organised with a global view and should be based on the competence that all maritime doctors should have to better respond to the seagoing professionals needs. In addition due to the rapid evolution of biomedical research health professional should invest in CPD to stay current and better serve their population. Furthermore, the model programme should be accredited by the responsible authorities and be flexible to accommodate the doctors' heavy workload. The provision of a relevant training course could help these medical specialties to better understand and respond to the needs of this hard to reach population group. The study builds on the international, national and scientific organizations policies and guidelines for continuous professional development, universal coverage and responsiveness to clients' needs and promote patient satisfaction [14]

Targeted training programmes are more effective as they built in self-ratings knowledge gaps of health professionals. Little is known about how maritime doctors perceive their own expertise, needs and challenges in relation to continuous professional development. The study intended to gain insight in maritime doctors perceived training needs with an aim at providing the background information to the respective authorities to organize a continuous professional development training programme as part of comprehensive maritime occupational health initiative to better respond to seagoing population health needs.

\section{Materials and Methods}

\section{Participants}

All participants were designated maritime doctors by the Danish Maritime Authority to provide the mandatory medical examinations of seafarers, fishermen, offshore workers and maritime students. As medical doctors show a low response rate the expected participation was set to about $50 \%$.

\section{Measurement}

A questionnaire was created in close cooperation with DMA and the Research Unit of General Practice, University of Southern Denmark, based on international experience [15] and adapted to Danish Standards. It draws on the ILO/IMO guidelines on the medical examinations for seafarers, the guidelines in occupational health training, coupled with the national respective ones as well as national and international medical experts' advice. It was pilot-tested in a small sample of maritime doctors to investigate content validity.

The survey instrument was self-administered and contained 40 items around four aspects of maritime medicine performance: Demographic characteristics, breadth of services offered to seafarers, fishermen, off-shore employees and marine students, follow-up practices and maritime doctors job satisfaction and perceived training needs. The instrument was developed with drop down menus to facilitate quick responses. The completion time of the questionnaire was about $7 \mathrm{~min}$. Here we present the outcomes concerning the maritime doctors perceived training needs.

\section{Data collection}

The survey took place electronically from 31 May to 28 June 2017. The survey was distributed electronically and anonymously via the Google Forms Analyse software. An e-mail was sent out to 84 e-mail addresses of maritime practices all over Denmark provided by DMA containing an invitation letter, explaining the scope of the survey and a link to the online version. Clinics with more than one affiliated maritime doctor were contacted by phone to make sure that all maritime doctors received the invitation e-mail. A total 110 designated maritime doctors were invited to participate. Three e-mail reminders were sent one week apart and the first one sent a week after the invitation letter to remind the doctors to participate in the survey. 51 (46.4\%) maritime doctors completed the survey.

\section{Statistical analysis}

STATA $^{\circ} 14$ statistical software was applied to analyse data descriptively. The importance of training needs was answered by the doctors on a five point Likert scale where 1 equalled 'not important' and 5 equalled 'very important'. We recoded the questions 37, 38, and 39 concerning job satisfaction into three categories; 'disagree or strongly disagree', neither disagree or agree' and 'agree or strongly agree'. In addition, the questions 40.1 to 40.15 were recoded into three categories: "not important", "moderately important" and "very important" to strengthen the robustness of the sample. Fisher exact test was used to examine associations between individual characteristics of health professionals including years of practice, number of maritime professionals visits and perceived training needs. In all cases a significance level of $\alpha=0.05$ was applied. The analysis of the results provided insights on issues and draw conclusions on their perceived training needs.

\section{Results}

Table 1 illustrates the demographics of the maritime doctors that participated in the survey. $43.11 \%$ of the maritime doctors were 60 years of age or older and the majority were men $(n=38,74.51 \%) .50$ doctors (98.04\%) had graduated from a University within Denmark and all doctors had Danish nationality. Two thirds of the population had more than 20 medical examinations of seafarers in 2016 and two doctors had none.

The topics on maritime doctors perceived training needs are presented in Table 2. Questions no. 37, 38 and 39 concerned doctors' job satisfaction and current knowledge to serve their maritime employees. The answers were ranked on a five point Likert scale where 1 equalled 'strongly disagree' and 5 equalled 'strongly agree'. Question no. 40 contains 15 sub-items, which were all ranked on a five point Likert scale, where 1 equalled 'not important' and 5 equalled 'very important.'

The study builds on the international, national and scientific organizations policies and guidelines for continuous professional development, universal coverage and responsiveness to clients' needs and promotes patient satisfaction [14].

The answers to the questions 37,38 and 39 were recoded into three categories; 'disagree or strongly disagree', neither disagree or agree' and 'agree or strongly agree'. Table 3 illustrates the answers to these items. The majority of doctors (88.3\%) who answered the question 37 agreed and strongly agreed that with their current knowledge are able to handle all cases effectively. $9.8 \%$ neither agreed nor disagreed while $2 \%$ strongly disagreed. With regards to the question 38, the vast majority $90.2 \%$ highlighted that they are satisfied with their job as maritime doctors. $9.8 \%$ answered that they are moderately satisfied and $2 \%$ are not at all satisfied. In relation to the question 39 the majority of maritime doctors 8 out of ten (76.4\%) agreed and strongly agreed that courses in maritime medicine can improve their knowledge. 15.7\% neither agreed or disagreed while $7.9 \%$ disagreed and strongly disagreed. 
Citation: Andrioti D, Faurby MD, Le JV, Jensen OC (2017) Do Danish Maritime Doctors Value Continuous Education Initiatives? Health Econ Outcome Res Open Access 3: 137. doi: 10.4172/2471-268X/1000137

Page 3 of 5

\begin{tabular}{|c|c|c|}
\hline & $\mathbf{N}$ & $\%$ \\
\hline \multicolumn{3}{|l|}{ Age } \\
\hline $40-49$ & 13 & $25.49 \%$ \\
\hline $50-59$ & 16 & $31.37 \%$ \\
\hline $60-69$ & 18 & $35.29 \%$ \\
\hline $70+$ & 4 & $7.84 \%$ \\
\hline Danish nationality (yes) & 51 & $100.00 \%$ \\
\hline Specialized in general medicine (yes) & 50 & $98.04 \%$ \\
\hline Gender (male) & 38 & $74.51 \%$ \\
\hline \multicolumn{3}{|l|}{ University } \\
\hline Aarhus & 21 & $41.18 \%$ \\
\hline Copenhagen & 16 & $31.37 \%$ \\
\hline Southern Denmark & 13 & $25.49 \%$ \\
\hline Outside of Denmark & 1 & $1.96 \%$ \\
\hline \multicolumn{3}{|l|}{ Years as a maritime doctor } \\
\hline$<5$ & 13 & $25.49 \%$ \\
\hline $5-9$ & 10 & $19.61 \%$ \\
\hline $10-20$ & 18 & $35.29 \%$ \\
\hline$>20$ & 10 & $19.61 \%$ \\
\hline $\begin{array}{l}\text { Medical examinations for other countries than } \\
\text { Denmark (yes, } n=15 \text { ) }\end{array}$ & 15 & $29.41 \%$ \\
\hline Norway & 9 & 60.00 \\
\hline United Kingdom & 7 & 46.67 \\
\hline The Netherlands & 2 & 13.33 \\
\hline Sweden & 2 & 13.33 \\
\hline Other & 7 & 46.67 \\
\hline \multicolumn{3}{|l|}{ Region } \\
\hline Capital & 9 & $17.65 \%$ \\
\hline Zealand & 4 & $7.84 \%$ \\
\hline Southern Denmark & 20 & $39.22 \%$ \\
\hline Central Denmark & 11 & $21.57 \%$ \\
\hline North Denmark & 7 & $13.73 \%$ \\
\hline \multicolumn{3}{|l|}{ Annual number of exams 2016: Seafarers } \\
\hline 0 & 2 & $3.92 \%$ \\
\hline $1-20$ & 8 & $15.69 \%$ \\
\hline$>20$ & 34 & $66.67 \%$ \\
\hline Don't know/don't recall & 7 & $13.73 \%$ \\
\hline \multicolumn{3}{|c|}{ Number of seafarers found not-fit-for duty in 2016} \\
\hline 0 & 15 & $29.41 \%$ \\
\hline $1-10$ & 29 & $56.86 \%$ \\
\hline Don't know/don't recall & 7 & $13.73 \%$ \\
\hline \multicolumn{3}{|l|}{ Annual number of exams 2016: Fishermen } \\
\hline 0 & 7 & $13.73 \%$ \\
\hline $1-20$ & 27 & $52.94 \%$ \\
\hline$>20$ & 9 & $17.65 \%$ \\
\hline Don't know/don't recall & 8 & $15.69 \%$ \\
\hline \multicolumn{3}{|c|}{ Number of fishermen found not-fit-for duty in 2016} \\
\hline 0 & 34 & $66.67 \%$ \\
\hline $1-10$ & 12 & $23.53 \%$ \\
\hline Don't know/don't recall & 5 & $9.80 \%$ \\
\hline \multicolumn{3}{|c|}{ Annual number of exams 2016: Offshore workers } \\
\hline $0-5$ & 20 & $39.22 \%$ \\
\hline $6-20$ & 15 & $29.41 \%$ \\
\hline$>20$ & 12 & $23.53 \%$ \\
\hline Don't know/don't recall & 4 & $7.84 \%$ \\
\hline \multicolumn{3}{|c|}{ Annual number of exams 2016: Maritime students } \\
\hline $0-5$ & 20 & $39.22 \%$ \\
\hline $6-20$ & 16 & $31.37 \%$ \\
\hline
\end{tabular}

\begin{tabular}{|l|c|c|}
\hline $\mathbf{2 0}$ & 13 & $25.49 \%$ \\
\hline Don't know/don't recall & 2 & $3.92 \%$ \\
\hline Electronic patient journals (yes) & 42 & 82.35 \\
\hline
\end{tabular}

Table 1: Maritime doctors characteristics $(\mathrm{N}=51)$

37: With my current knowledge in the medical examination of seafarers am I able to handle all cases confidently

38: I am satisfied with my current position as a Maritime Health Physician

39: Training in maritime medicine could increase my knowledge

40.1 Rules and regulations within maritime medicine

40.2 Organisation of Maritime Health Services and Resources in Denmark and abroad

40.3 Telemedicine/radio medical advice

40.4 Occupational disease diagnostics, prevention and reporting

40.5 Health and safety at work

40.6 How to do early diagnosis, prevention and follow-up of common chronic conditions (e.g. diabetes, overweight/obesity and hypertension) at seafarers

40.7 Working conditions and health risks on board

40.8 Medical communication between doctor and patient

40.9 Gender issues

40.10 Maritime medicine emergencies

40.11 On board/Shipboard medicine

40.12 Fitness evaluation and Medical Examination Guidelines

40.13 Clinical registers for follow-up and research of seafarers

40.14 WHO/International Health Regulations (IHR)

40.15 Information management

Table 2: Overview of topics related to the item on maritime doctors' job satisfaction and perceived training needs.

Topic

N $\quad \%$

40.12. Fitness evaluation and Medical Examination Guidelines $39 \quad 76.47 \%$

\begin{tabular}{|l|l|l} 
40.1. Rules and regulations within maritime medicine & 35 & $68.63 \%$
\end{tabular}

\begin{tabular}{|l|l|l|}
\hline 40.7. Working conditions and health risks on board & 32 & $62.75 \%$
\end{tabular}

\begin{tabular}{|l|l|l|}
\hline 40.10. Maritime medicine emergencies & 29 & $56.86 \%$ \\
\hline
\end{tabular}

\begin{tabular}{|l|l|l}
\hline 40.11. On board/Shipboard medicine & 29 & $56.86 \%$
\end{tabular}

\begin{tabular}{|l|l|l|}
\hline 40.5. Health and safety at work & 25 & $49.02 \%$
\end{tabular}

\begin{tabular}{|l|l|l}
\hline 40.15. Methods for professional update & 22 & $43.14 \%$
\end{tabular}

\begin{tabular}{l|l|l|} 
40.2. Organisation of Maritime Health Services and Resources & 19 & $37.25 \%$
\end{tabular}

in Denmark and abroad

$.25 \%$

\begin{tabular}{|l|l|l|}
\hline 40.3. Telemedicine/radio medical advice & 17 & $33.33 \%$ \\
\hline
\end{tabular}

\begin{tabular}{|l|l|l|} 
40.14. WHO/International Health Regulations (IHR) & 16 & $31.37 \%$
\end{tabular}

40.6. How to do early diagnosis. prevention and follow-up of

common chronic conditions (e.g. diabetes. overweight/obesity $16 \quad 31.37 \%$

and hypertension) at seafarers

40.13. Clinical registers for follow-up and research of seafarers $15 \quad 29.41 \%$

40.4. Occupational disease diagnostics. prevention and 14 27.45\% reporting

\begin{tabular}{|l|l|l}
\hline 40.8. Medical communication between doctor and patient & 13 & $25.49 \%$
\end{tabular} 40.9. Gender issues

$11 \quad 21.57 \%$

Table 3: Question no. 40 on maritime doctors training needs ranked according perceived importance.

Differences in the rating of knowledge, satisfaction and perceived importance of training needs were analysed according to personal characteristics of the maritime doctors such as: Gender, years as a maritime doctor, annual number of seafarer exams, region of clinical practice and age and differences were tested with Fisher exact test at a confidence interval 95\%.

Age, gender, region and years in practice as a maritime doctor did not show any statistically significant influence on their knowledge or satisfaction. Only the number of seafarers exams did have a statistical 
significant influence on their perception to handle all cases confidently, where $40 \%$ of maritime doctors with 20 or less annual exams disagreed or strongly disagreed compared to 5.88 percent of the doctors with more than 20 annual exams $(\mathrm{p}=0.031)$.

The question 40 was recoded into three categories: "not important", "moderately important" and "very important".

Table 3 presents the ranking of the doctors perceived training needs according to the perception of the topic being very important. The topic 40.12 "Fitness evaluation and medical examination guidelines" was the topic which most of the maritime doctors perceived to be very important and got the highest ranking among the 15 topics. In addition, more than half of the maritime doctors perceived training in 40.1 "Rules and regulations within maritime medicine", 40.7 "Working conditions and health risks on board", 40.10 "Maritime medicine emergencies" and 40.11 "Shipboard medicine" to be very important topics, highlighting the five training priorities. On the contrary at the bottom of their preferences was listed the question 40.9 "Gender issues". This was the topic that were perceived by least maritime doctors to be very important (21.6\%), followed by 40.8 "Medical communication between doctor and patient" and 40.4 "Occupational disease diagnostics, and prevention, which less than $30 \%$ of the maritime doctors perceived to be very important.

In general, the maritime doctors' perceived training needs did not differentiate according to gender. Furthermore, Region of practice did not influence the perception of the importance of training needs except for topic three, where a statistically significant difference was observed at the $95 \%$ significance level. More specifically 40.3 "Telemedicine/ radio medical advice was pointed out as a very important topic to the Region Capital ( $\mathrm{p}=0.005)$.

Age had some influence on the perception of the importance of the different topics, where statistically significant differences were observed for topics 40.11 and 40.12 . In the perception of "On board/ Shipboard medicine $84.62 \%$ in the 40 to 49 age group, perceived this topic to be very important ( $\mathrm{p}=0.001$ ). With regards to the topic 40.12 "Fitness evaluation and Medical Examination Guidelines all doctors aged 40 to 49 perceived the topic to be very important $(\mathrm{p}=0.040)$.

The perception of the importance of the training needs did not depend on the years practised as a maritime doctor $(p>0.05$ in all cases). According to the annual number of seafarer exams there were statistically significant difference towards topic 40.15 . Maritime doctors conducting more than 20 seafarers health exams perceived "Information management" to be more important (55.88\%) than doctors conducting 20 or less health exams $(10.1 \%)$, to receive training $(\mathrm{p}=0.017)$.

\section{Discussion and Conclusion}

This study is part of a comprehensive research targeting maritime doctors in Denmark. This is in order to improve the occupational health of seagoing professionals based on scientific knowledge. The education and training programmes form the basis for the strategic prevention programme followed by the monitoring of the outcomes. The need for new national and international guidelines and recommendations will be disclosed to minimise some risk factors that will else not be changed. The present survey comprised of closed and open free-text questions, targeted maritime doctors in an attempted to explore Continuous Professional Development (CPD) training needs. This was the first study to explore systematically the expertise, needs and problems of maritime doctors dealing with international community employees as the people who work at sea originate from all over the world.
The guidelines on pre-engagement health examinations point out that the authorities should have in place the institutional settings to meet the needs of seagoing population providing high quality health services. Due to the nature of the work at sea, maritime doctors should have a clear understanding of the living and working conditions in ships. These qualifications may include occupational health or maritime health qualifications, experience of working as a ship doctor or as doctor in a shipping company. The competent authorities should have in place relevant additional guidance for GPs. They should take into consideration that GPS may need more detailed guidance than medical practitioners with competence in maritime health.

Even though a minimum set of international guidelines on fit-towork-examinations exist, each authority and shipping company may require more comprehensive medicals. As a result companies may face a higher cost contributing in a negative way to their profitability. Therefore it is essential a minimum set of high quality examinations provided by accredited maritime doctors around the globe. The cooperation of all relevant stakeholders is very important.

Continuing education programmes enable physicians to better respond to their populations needs and expectations and improve patient centred care by educating patients on health prevention related to chronic diseases, including hypertension, diabetes and cardiovascular diseases [16]. So far despite the relevant guidelines issued by the responsible International Organisations including the International Labour Organisation and the International Maritime Organization, there is a lack of an internationally accepted continuous professional training programme for the maritime doctors. As they perform the pre-engagement examinations for the seagoing professionals, their performance is of crucial importance for the shipping industry and the employees in particular. Seafarers sail the high seas, they are requested to be in good health to perform their duties. Sickness far away from shore can be not only dangerous for the infected employee but also for the fellow colleagues while evacuations are proved very expensive for the industry. It is important to update their knowledge and be familiar with the living and working conditions on board as well as the specific law and regulations with regards to the seafaring. The National Health Systems and the shipping industry will benefit from lower hospitalization and evacuation costs by offering higher quality of services.

This study added new knowledge by investigating the expertise of and challenges faced by this sector. It found areas of knowledge that need to be updated to enable maritime doctors to optimize their services according to the needs of their seagoing population [6]. As expected the majority of maritime doctors highlighted the need for targeted training in five areas of priority: "Fitness Evaluation and Medical Examination Guidelines" followed by "Rules and regulations within Maritime Medicine" "Working conditions and health risks on board", "Medical Emergencies" and "Shipboard medicine". The number of health examinations has a statistically significant influence in their training needs, as well as in their job satisfaction, while age, gender and Region did not show any influence on their answers. In the bottom of their preferences, they listed "Gender discrimination" and "Communication with patients" possibly because the Danish society had actively been working on these and they are of limited concern. With regards to the topic of "Occupational diseases, diagnosis and prevention" the maritime doctors may feel that it is beyond their spectre of services offered to the maritime professionals.

The maritime doctors in Denmark expressed a big interest in professional development despite the concerns of the respective associations and furthermore, they made suggestions on the way that the training should be organized to comply with their high work 
burden. In line of this they pointed out the need for the establishment of an Advisory Board for active authoritative guidance and a website as one stop-shop with relevant guidelines and information for maritime doctors. The research provided the opportunity to benchmark the situation in Denmark and allows for international comparison on doctors' perceived training needs in other countries.

The results of this study may help the respective Authorities to organise training for continuing professional development of these medical specialties. Well-trained professionals provide quality services that meet the expectations and demands of the population and contribute to patient safety. A successful CPD training initiative should be introduced in cooperation with all relevant stakeholders (authorities, shipping industry, medical doctors, academia and maritime professional associations) and should be flexible to accommodate doctors' heavy workload. Such curriculum should build on maritime occupational and environmental health. In addition, laws and regulations, communications with authorities, issues of multicultural and public health should be taken into consideration. Furthermore, to enhance the sustainability of this model programme, with minimum requirements, should be accredited by the responsible authorities.

\section{Study Limitations}

In this survey 51 maritime doctors $(46.4 \%)$ completed the questionnaire. It is well known that medical doctors show fairly low response rates, but the sample is very close to the expected response rate of $50 \%$. Denmark is a small country and the team made efforts to include all the 110 maritime doctors. The response rate includes almost half of them; however a larger sample may provide more representative results.

\section{Authors' Contributions}

DA and OCJ designed the study, applied for approval to the Danish Data Protection Agency, created the study instrument, substantially contributed to the interpretation of the data and provided comments on all drafts. MDF carried out the data gathering and data analyses as well as drafted the initial manuscript. JVL actively participated in the design of the survey instrument, supported the data gathering and provided comments on all drafts. All authors confirm that this manuscript describes original work and has neither been published or submitted for publication elsewhere. All authors read and approved the final manuscript.

\section{Ethics Approval}

The study was approved by the Danish Data Protection Agency.

\section{Funding}

The project was co-financed by the Danish Maritime Fund.

\section{References}

1. Henny C, Hartington K, Scott S, Tveiten A, Canals L (2013) The business case for telemedicine. Int Marit Health 64: 129-135.

2. Lefkowitz RY, Slade MD, Redlich CA (2015) Risk factors for merchant seafarer repatriation due to injury or illness at sea. Int Marit Health 66: 61-66.

3. Poulsen TR, Burr H, Hansen HL, Jepsen JR (2014) Health of Danish seafarers and fishermen 1970-2010: What have register-based studies found? Scand $J$ Public Health 42: 534-545.

4. Andrioti D, Jensen O (2017) Maritime Doctors and General Practitioners Service Profiles: A Research Protocol. Health Sci J 11: 2.

5. International Maritime Organization (2013) Guidelines on the medical examinations of seafarers. Geneva: ILO.

6. International Labour Organization (2006) Maritime Labour Convention, 2006 Geneva.

7. Legal Information (2013) Executive order on medical examination of seafarers and fishermen. Ministry of Trade and Industry.

8. Danish Maritime Authority (2017) Application to become a maritime doctor.

9. World Health Organization (2006) Working together for health. Geneva: World Health Organisation.

10. Regnier K, Kopelow M, Lane D, Alden E (2005) Accreditation for learning and change: quality and improvement as the outcome. J Contin Educ Health Prof 25: 174-182.

11. Overstreet K, Eidsvoog K, Orsetti R (2006) Educational interventions and outcomes-a literature review of CME regarding institute of medicine (IOM) competencies. CE Meas 1: 17-26.

12. OECD (2010) Value for money in health spending. Paris: OECD.

13. Kickbusch I, Pelikan JM, Apfel F, Tsouros AD (2013) Health literacy: the solid facts. Copenhagen: World Health Organization Regional Office for Europe.

14. Carter T, Stannard S (2014) Healthcare at sea: are regulations a guarantee of minimum standards or a barrier to improved practice? Int Marit Health 65 177-180.

15. Alcaraz M, Solomon E, Ching S, Paul M, Teves P, et al. (2016) Current profile of filipino physicians doing medical examination of seafarers in the Phillippines: Need for maritime medicine training? Int Mar Health.

16. Lucero-Prisno D, Muramatsu S, Hisamune S, Ehara M (2005) Mainstreaming health in maritime education and training. Int Marit Health pp: 300-302. 